\title{
Netherlands Society of Allergy
}

Meeting at Amsterdam, April 13th, 1957

President: Dr. C. de Lind van Wyngaarden The Symptomatic Treatment of Allergic Phenomena By F. A. Nelemans, Utrecht

From the therapeutic point of view it is allowed to suppose that allergic phenomena are caused by a local liberation of an excess of histamine; that means that the symptomatic therapy of these phenomena can be done as if one has to deal with a local reaction of histamine.

The drugs for this therapy can be divided into several groups:

Physiological antagonists, as adrenaline and its derivatives; and partially calcium compounds; Competitive antagonists, as the so-called anti-histaminics;

Histamine destructing substances (histaminase);

Substances, diminishing the reactivity of the body, as cortisone and (via the adrenals) AGTH; Substances, which antagonise the liberation of "histamine", such as local anesthetics (procaine) and sedatives (phenobarbital), as well as general anesthetics (ether);

Substances, which inhibit certain reactions symptomatically (e. g. spasmolytics, contractions of smooth muscle).

Generally speaking, one does not find starting points for the treatment in the constitution of the patient; on the other hand, it is worth-while considering the allergic phenomena as such.

The pharmacology of histamine gives us the most important features:

an increased permeability of the capillaries and a strong dilatation;

A contraction of practically all smooth muscles;

An increased secretion of many glands (stomach, saliva, mucous gland). In the different allergic phenomena one finds as a rule one or more of the above

mentioned reactions, either directly or the sequences of it. In these cases in which the increased permeability of the capillaries, their strong dilatation (hay fever) or the contraction of smooth muscles are the most prominent features, anti-histaminics are the drugs of choice. Itching, too, can be cured by them (urticaria, serum-sickness). Under life-threatening circumstances, an initial therapy with adrenaline will be preferable, as by such a therapy results are obtained more quickly (angioneurotic edema of the glottis).

In cases where there is an increased secretion, the administration of anti-histaminics is useless; on the other hand parasympathicolytics or sympathicomimetics (bronchial asthma) may be beneficent. It need not be specially mentioned that the above mentioned therapy can be supported by an additive treatment (e.g. calcium intravenously, phenobarbital, procaine). Topical application of cortisone-derivatives (e. g. on the skin) does not influence the general metabolism; an internal use does influence the metabolism to such an extent, that AGTH and cortisone as symptom-suppressing drugs may only be used on strict and urgent indication. Proceedings - Gesellschaftsberichte - Sociétés

255

Some Aspects of the Allergic Mechanism By K. de Vries, Groningen 
The term "allergy" is briefly discussed. The basic mechanism of allergy is an antigen-antibody reaction. The chemical qualities (e. g. determinant groups, radical acid groups etc.) of a substance which constitute the antigenic properties are reviewed. These qualities are not uniform. Substances may vary in antigenicity in several aspects. The antibodies to a definite antigen may also vary in specificity, serological and physico-chemical aspects depending on the species of the used animal, route of administration of the antigen, intensity of the immunization (sensitization) procedure etc. The factors determining the serological reaction are discussed with special reference to the different possibilities of biochemical ways of antigen-antibody interactions. These data are obtained from experimental sources.

There are some difficulties with respect of allergy:

The lack of knowledge of the chemical structure of allergens and their antigenic patterns. The insufficient understanding of the immunization (sensitization) procedure.

The modified antibody formation in allergic patients. The different antibodies and their properties are summarized: reagins, blocking-antibodies, microprecipitins and precipitins. Finally the cellular and humoral hypotheses of anaphylaxis and allergic phenomena are reviewed with special reference to the chain reactions.

Urticaria

By W. J. F. van den Bijl, Amsterdam

The history of patients with urticaria and the histo-pathological features of this condition are briefly reviewed in an introductory comment, in which special stress is laid on the frequent appearance of allergic anatomical-functional reactions of the capillary system in the upper papillary portion of the skin, although attention is also drawn to the fact that the "histamine theory" has been more or less generally accepted as directly or indirectly explaining the pathogenesis in the majority of cases. This comment is followed by a report on two cases of urticaria.

One case was that of a 27-year-old nurse who had constantly had attacks of urticaria at home up to the age of five. The family lived in an old dusty house, where they carried on a furniture business. When staying with relations, she was not affected with urticaria. There had never been any evidence of food allergy. After she had moved to another house at a seaside resort, all symptoms of urticaria disappeared immediately.

When she was on holiday in June last year, she developed pollinosis, the attacks disappearing after September. She came to see us in January, so as to be in time to take a course of desensitization treatment. The results of intradermal tests using grass and maize pollen were markedly positive, whereas those with rye pollen were doubtful.

Of the tests using other allergens, only those made with extracts of house dust were markedly positive (4 cm in diameter and a wheal with pseudopods). Although the patient was not aware of the nature of the substance used in the tests, she responded by developing a number of goodsized urticarial eruptions on the extremities $\mathbf{4 5}$ minutes later. Accordingly, she had obviously been sensitized to house allergens when she was a child and had retained these specific sensitizations throughout life.

The other patient developed urticaria shortly after birth; he caused infection of the eruptions by constant scratching. When he was 3 years old, the wheals disappeared completely, but at the age of 28, when he was employed in a shop where there was always plenty to do, there was an unfortunate day when he knocked his right thumb

256

News Items - Nachrichten - Nouvelles 
hard against the front edge of a shelf in putting away a crate, which resulted in a severe subcutaneous haemorrhage beneath the nail-bed. Fifteen minutes later, he showed a generalized outbreak of urticaria. A physician living in the neighbourhoodjgave an injection of $0.5 \mathrm{ml}$. of a 1:1 000 solution of adrenaline. This treatment failed, however. I saw the patient within one hour after the injury had been sustained. His entire body was covered with urticarious wheals. An antihistaminic (sandosten calcium plus calcium Sandoz) was immediately injected intravenously and a tablet was given orally, and this treatment was followed by the disappearance of all symptoms within 90 minutes.

What were the possible causes of this severe attack? In my opinion, the primary and chief cause was the liberation of histamíne which was released from the injured tissue into the blood stream and thus gave rise to the shock. This theory was formulated in principle by Lewis in 1927. Cell protein cannot possibly be converted into histamine within such a short space of time. Therefore, this must have been histamine liberated at the afferent nerve-endings as a result of the injury. Hoff claims that primary damage to the skin cells may induce chemical changes in the cell substance, which may result in sensitization of the skin of the entire body. Recurrence of the injury may give rise to a shock-like allergic reaction. According to Hoff's theory, the patient might even have been sensitized in his early childhood.

I do not believe, that this reaction could have been due to Schmidt's so-called auto-antibodies. Accordingly, I assume that, in addition to the above "histamine shock", pressure of work resulting in a lowered mental and physical resistance, must have predisposed the body of the patient to this shock.

I did not see the patient again in the out-patient department, so that I was not able to run a Prausnitz-Küstner test. However, I do not believe that this test would have revealed the presence of any reagin.

News Items - Nachrichten - Nouvelles

Netherlands Society of Allergy

In order to honour the name of the great Dutch allergologist Storm van Leeuwen and to express its great appreciation of the work done by other allergologists, the Dutch Allergy Society has decided to institute the "Storm van Leeuwen Medal".

This medal will be awarded once every five years and the recipient will be invited to give a lecture on his work. The Storm van Leeuwen Medal will be presented for the first time in May 1958. With regard to his splendid achievements in the field of allergology, the members of the Dutch Allergy Society have requested Dr. F. M. Rackemann (Boston) to accept the medal. Prof. G. W. Pickering Honoured In recognition of his distinguished services to medicine, a knighthood has been conferred on Prof. Pickering, Regius Professor of Medicine at Oxford. Formerly Professor of Medicine at St. Mary's Hospital, London, Prof. Pickering is a founder-member of the Collegium Internationale Allergologicum. 